\title{
Evaluating derived vegetation indices and cover fraction to estimate rangeland aboveground biomass in semi-arid environments
}

\author{
Nahom Gudeta Fajji ${ }^{1}$, Lobina G Palamuleni ${ }^{1}$, Victor Mlambo ${ }^{2,3}$ \\ ${ }^{1}$ Department of Geography and Environmental Sciences, North-West University, P Bag x2046, \\ Mmabatho, 2735, South Africa. \\ ${ }^{2}$ Department of Animal Sciences, School of Agricultural Sciences, North-West University, P \\ Bag x2046, Mmabatho, 2735, South Africa. \\ ${ }^{3}$ Food Security and Safety Niche Area, Faculty of Agriculture, Science and Technology, North- \\ West University, P Bag x2046, Mmabatho, 2735, South Africa
}

DOI: $\underline{\text { ttp: } / / / d x . d o i . o r g / 10.4314 / s a j g . v 6 i 3.5}$

\begin{abstract}
This study was conducted to assess satellite data for quantifying and mapping the spatial distribution of rangeland biophysical parameters (aboveground biomass) from different geographic locations in the North West province, South Africa. Two major factors affecting the quality and conditions of the rangelands, namely rainfall zones and grazing intensities, were used to define sampling classes to represent the predominantly Savanah environment. Remote sensing vegetation indices (NDVI and SAVI) and vegetation cover fraction (SMA) were used to quantify the aboveground biomass using regression models of the sample aboveground biomass as a function. Results showed that private ranches in high rainfall areas yielded the highest aboveground biomass (159 kg $\left.100 \mathrm{~m}^{-2}\right)$ while the lowest biomass yield (10 kg $\left.100 \mathrm{~m}^{-2}\right)$ was obtained from the communal rangelands in the low rainfall area. The SAVI performed well (0.64) in the low rainfall areas but the coefficient of determination between the AGB and SAVI was not significant (at $p \leq 0.05$ ). The SMA also performed better than the NDVI (0.53) in the low rainfall areas but because of its weaknesses (0.57 and 0.48) in the high and medium rainfall areas, respectively, this tool is not ideal for quantifying AGB in the North West Province. In spite of its weakness in the low rainfall areas (0.47), the NDVI had displayed stronger coefficient of determination (0.63 and 0.70) with the $A G B$ in the medium and high rainfall zones respectively. From a management perspective, remote sensing techniques appears to be a good alternative for managing and monitoring spatial and temporal AGB production, which is a major determinant for rangeland quality assessment
\end{abstract}

\section{Introduction}

One of the major applications of remote sensing in the field of environmental resources management and decision-making is the detection and quantitative assessment of green vegetation (Silleos et al. 2006). Measuring the biophysical parameters of rangeland vegetation condition for accurate prediction of its productivity and management is essential as these ecosystems provide a steady supply of goods and services. Quantifying vegetation abundance and other biophysical parameters such as biomass, leaf area index, vegetation density, canopy height and live biomass 
quantity in rangelands is very important for identifying the effects of different natural and atmospheric factors (Wu et al. 2013). However, in situ techniques employed for determining these biophysical parameters are labour intensive, costly, need complex calibration techniques and are not suitable for regional analyses (Elmore et al. 2000).

A repeatable monitoring technique for rangeland conditions is an essential factor for developing knowledge of important ecological processes and for conservation purposes (Guo et al. 2004). Hence, remote sensing is a very important source of data suitable for rangeland management practices. It is possible to analyse, model and simulate the biophysical properties of vegetation in different wavelengths of the electromagnetic spectrum (Jarocinska \& Zagajewski 2006). Multispectral satellite data can be used for assessing vegetation health, land cover and quantifying aboveground biomass in rangelands using vegetation indices and spectral mixture analysis (Booth \& Tueller 2003). Vegetation indices are derived by mathematically combining various bands of satellite data (Tueller 1996). Vegetation indices and spectral mixture analysis (SMA) are leading methods that can overcome certain characteristic difficulties that are related to usage of radiance data for quantifying vegetation abundance in comparable units to field measures (Elmore et al. 2000).

Spectral vegetation indices utilize unique spectral signatures of green vegetation. Different types of vegetation often show typical variability from one another due to different parameters such as shape and size of plants, water content, and associated background. Vegetation indices are applicable to both low and high spatial resolution multispectral satellite sensors, such as NOAA AVHRR, Terra MODIS, Landsat Thematic Mapper (TM) and MSS, SPOT HRV/XS, and many others that acquire data in the visible and near-infrared regions. Vegetation indices have been used in a variety of frameworks to assess green biomass and also as an alternative to overall environmental change, especially in the context of drought, land degradation risk assessment and rangeland management (Liu et al. 2005; Wessels et al. 2007; Numata et al. 2007). Different vegetation indices have been developed based on the combinations of two or more spectral bands, assuming that multi band analysis would provide more information than a single one. Vegetation indices use radiance, surface reflectance or apparent reflectance values in the red $(\mathrm{R})$ and near infrared (NIR) spectral bands (Gitelson, 2004; Tucker et al. 2005; Zoran \& Stefan 2006; Brown et al. 2006; Angerer 2009). These indices are correlated with various vegetation parameters such as green biomass (Mutanga et al. 2012; Ullah et al. 2012), chlorophyll concentration (Clevers \& Kooistra 2012), leaf area index (Mountrakis et al. 2011; Yang et al. 2012) and photosynthetic activity (Tueller 1989; Huete et al. 2002; Li et al. 2010).

In South Africa, rangelands cover more than $80 \%$ of the land surface and are critical for sustained supply of essential ecosystem goods and services. These resources contribute highly to the economic development of the country through agriculture and provision of food products (Masigo \& Matshego 2002). Large and small scale commercial and subsistence livestock production depends largely on rangelands. In the North West province of South Africa, degradation of 
rangeland is of concern mainly because of the long history of environmental and political neglect; and over utilization of the land. Hoffman \& Todd (2000) and Wessels et al. (2007) reported that highly degraded communal lands are characterized by high human and livestock density, overgrazing, soil erosion and the loss of more palatable grass species and bush encroachment. Given the high growth rate of the human population resulting from natural increase and forced resettlement, communal lands of the North West Province have been highly degraded due to overgrazing and intensive farming (Wessels et al. 2004). Fragmentation of rangelands caused through politically induced racial discrimination resulted in an uneven distribution and privatization of land. This coupled with droughts, a common phenomenon of the region; laid a foundation for high disparities in the level of rangeland productivity and management between communal, commercial and protected lands in the province (Vogel \& O’Brien 2003).

However, quantitative measures of rangelands under these conditions and their change in space and time due to degradation have not been reported in this area inclusively. Few studies have been made to understand the differences in the level of degradation of these rangelands (Shackleton 1993; Snyman 1998; Hoffman et al. 1999; Dube \& Pickup 2001; Wessels et al. 2004; Wessels et al. 2007; Munyati \& Mboweni 2013). This is mainly due to lack of well-established methodology for the assessment and quantification of the qualities of these rangelands. Therefore, this study is an attempt to assess the ability of remote sensing SPOT-5 data in extracting and mapping rangeland biophysical information in three rainfall zones in the North West province of South Africa. Vegetation indices and vegetation fractions (Normalized Difference Vegetation Index (NDVI), Soil Adjusted Vegetation Index (SAVI) and the SMA) were computed and integrated with field based data using a regression technique. The focus of the study was to compare the effectiveness of the differently derived vegetation indices in quantifying AGB from private ranches, communal areas and protected areas within predefined rainfall and grazing intensity sampling classes.

\section{Description of the study area}

The North West province of South Africa is located between $22^{\circ} 39^{\prime} 21^{\prime \prime}$ E and $25^{\circ} 17^{\prime} 28^{\prime \prime} \mathrm{E}$ and $24^{\circ} 43^{\prime} 36^{\prime \prime S}$ and 28 00'00"S. It includes four districts namely: Ngaka Modiri Molema, Bojanala, Dr. Kenneth Kaunda, and Dr. Ruth Segomotsi Mompati. Most of the North West province (71\%) falls within the Savanah Biome, while the remaining part falls within the Grassland Biome (Mangold et al. 2002). 


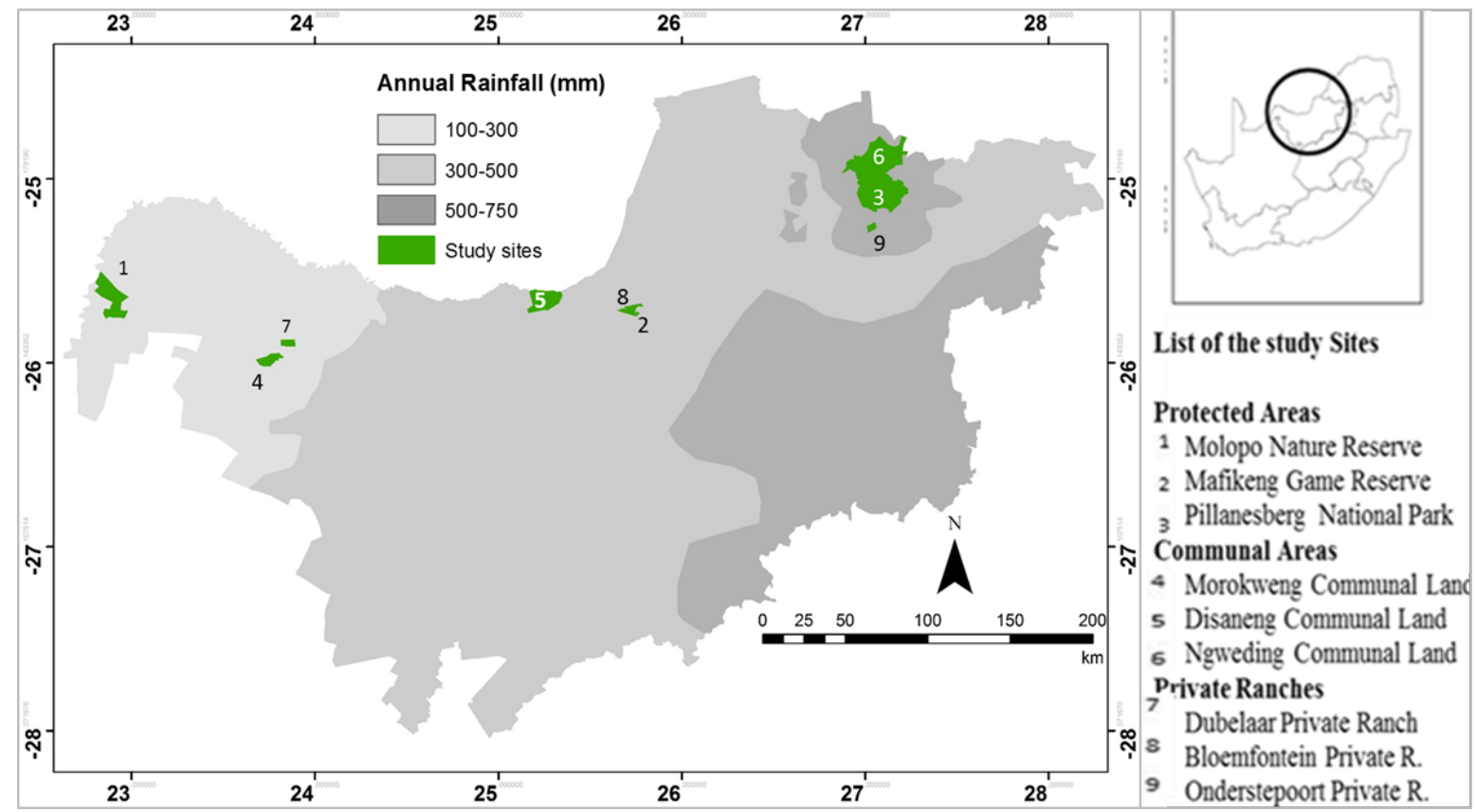

FIG. 1. Map of the North West province and the locations of the study sites

According to Schultze (1997) and Hudson (2002), there are four types of ecological zones in the province, namely: the Highveld in the south-east, the Bushveld in the north-east, and the Middleveld as a narrow zone between the Highveld and the Bushveld, and the Kalahari Desert in the west. The province has the most uniform terrain of all the provinces, with an altitude ranging from 920-1782 metres above sea level (Mangold et al. 2002).

\section{Materials and methods}

The data which were used in this study included harvesting of aboveground biomass from the different study sites and satellite SPOT-5 imagery obtained from the South Africa National Space Agency (SANSA).

\subsection{Field Data}

A field survey was conducted during late February to early April, 2014 when the vegetation reaches its maximum growth level in the study region. The sampling sites were selected based on cost and accessibility. Study sites were sampled along a pre-defined rangeland moisture gradient using a randomized block sampling technique. The data were collected from different spatial locations by dividing the North West province into three distinctive zones (Table 1). 
Table 1: Description of the study sites

\begin{tabular}{|c|c|c|c|c|c|c|}
\hline \multirow[b]{3}{*}{ Study Sites } & \multirow[b]{3}{*}{ Total Area } & \multirow{3}{*}{$\begin{array}{l}\text { Rangeland } \\
\text { Regime }\end{array}$} & \multicolumn{4}{|c|}{$\begin{array}{l}\text { Average sample forage weight } \\
\text { from high and low grazing } \\
\text { intensities }\left(\mathrm{kg} / 16 \mathrm{~m}^{2}\right)\end{array}$} \\
\hline & & & \multicolumn{2}{|c|}{ Wet Weight } & \multicolumn{2}{|c|}{ Dry Weight } \\
\hline & & & HGI & LGI & HGI & LGI \\
\hline \multicolumn{7}{|l|}{ Low Rainfall zone } \\
\hline $\begin{array}{ll}\text { Molopo } & \text { Nature } \\
\text { Reserve } & \end{array}$ & $240 \mathrm{~km}^{2} / 24000 \mathrm{ha}$ & Protected Area & 25.7 & 43.16 & 8.35 & 12.93 \\
\hline Morokweng & $65 \mathrm{~km}^{2} / 6500 \mathrm{ha}$ & $\begin{array}{l}\text { Communal } \\
\text { Area }\end{array}$ & 14.28 & 23.35 & 4.67 & 12.10 \\
\hline Dubbelaar & $2.80 \mathrm{~km}^{2} / 280 \mathrm{ha}$ & Private Ranch & 40.80 & 60.73 & 12.91 & 23.69 \\
\hline \multicolumn{7}{|l|}{ Medium Rainfall Zone } \\
\hline $\begin{array}{ll}\text { Mafikeng } & \text { Game } \\
\text { Reserve } & \\
\end{array}$ & $48 \mathrm{~km}^{2} / 4800 \mathrm{ha}$ & Protected Area & 41.57 & 85.73 & 12.25 & 25.81 \\
\hline Disaneng & $179 \mathrm{~km}^{2} / 17900 \mathrm{ha}$ & $\begin{array}{l}\text { Communal } \\
\text { Area }\end{array}$ & 22.10 & 43.2 & 6.64 & 13.18 \\
\hline Lenric & $1.87 \mathrm{~km}^{2} / 187 \mathrm{ha}$ & Private Ranch & 78.1 & $\begin{array}{l}149.0 \\
2 \\
\end{array}$ & 23.43 & 44.7 \\
\hline \multicolumn{7}{|l|}{ High Rainfall Zone } \\
\hline Pilanesberg & 490km²/49000ha & Protected Area & 48.78 & 95.16 & 14.63 & 28.53 \\
\hline Ngweding & 406km²/40635ha & $\begin{array}{l}\text { Communal } \\
\text { Area }\end{array}$ & 27.68 & 56.51 & 6.60 & 16.83 \\
\hline Onderspoort & $17.17 \mathrm{~km}^{2} / 1717 \mathrm{ha}$ & Private Ranch & 80.22 & 154.1 & 24.71 & 48.34 \\
\hline
\end{tabular}

Note: HGI (High Grazing Intensity), LGI (Low Grazing Intensity)

The major criterion for categorizing the study sites into different zones was amount of precipitation. The climate of the province is characterised by well-defined seasons with hot summers and cool sunny winters. According to FAO's annual rainfall distribution and climatic classification in South Africa, the North West province can be classified into three major rainfall zones based on the average rainfall received, namely: arid (low rainfall zones (200 - $400 \mathrm{~mm}$ )), semi-arid (medium rainfall zones, (401 - $600 \mathrm{~mm}$ )), and sub-humid (high rainfall zone, (601- 800 mm) (FAO, 2006). 


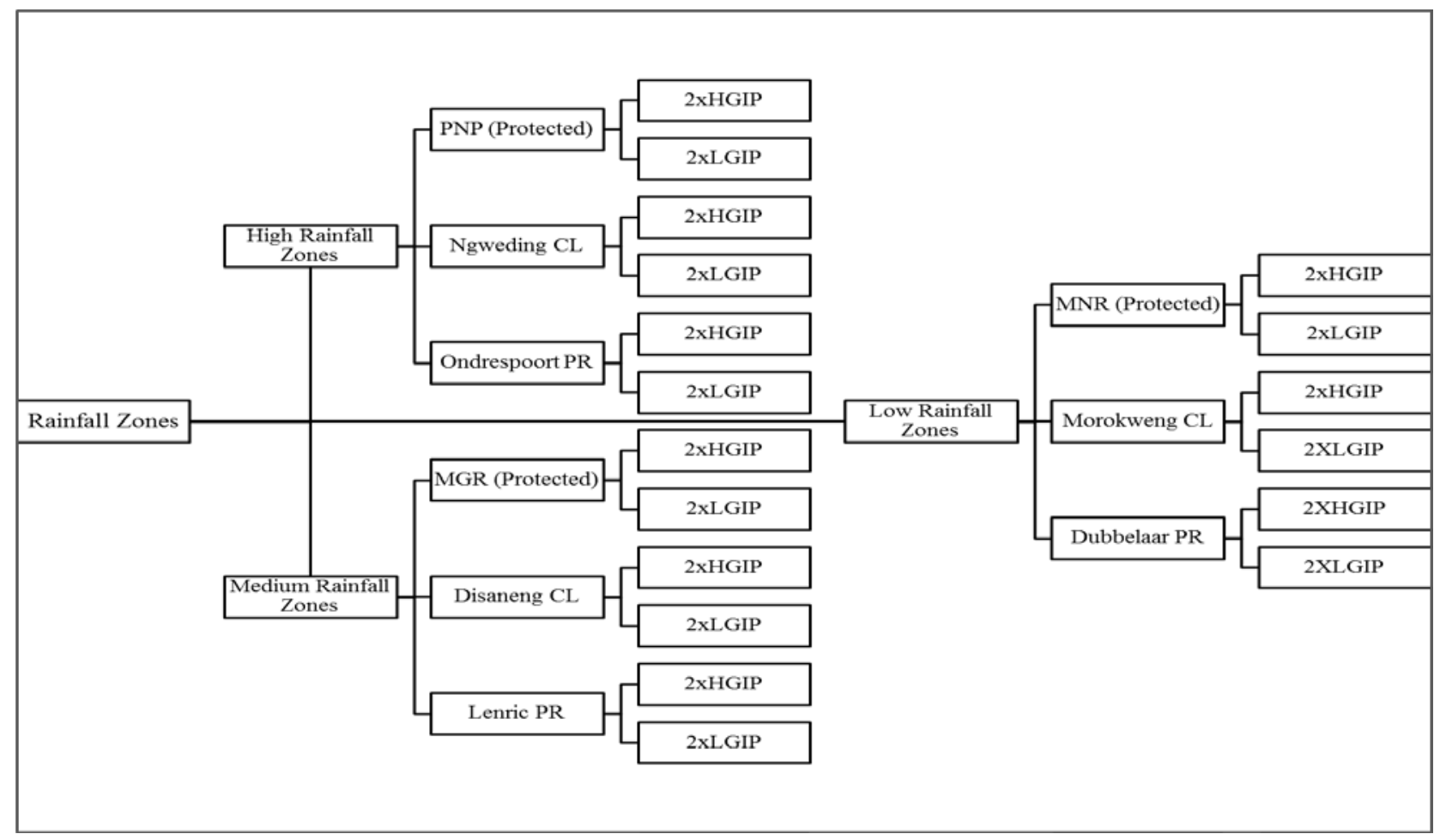

FIG. 2. A flow chart of the field data collection process.

Note: PNP (Pilanesberg National Park), MGR (Mafikeng Game Reserve), MNR (Molopo Nature Reserve), CL (Communal Land), PR (Private Ranch), HGIP (High Grazing Intensity Plot), LGIP (Low Grazing Intensity Plot)

Rainfall varies from the more mountainous and wetter eastern region to the drier, semi-desert plains of the Kalahari in the west. The rainy season usually occurs from October to March, which is the summer season characterised by more sunshine days and warm temperatures. In addition, there are three major types of rangeland regimes in the province, namely: protected areas, communal lands and private ranches. From each rainfall zone, three rangeland regimes that were in close proximity to each other were selected randomly. Thereafter, the sites were subdivided into low and high grazing intensity units using ocular cover estimate technique (Daubenmire 1959) based on the quantity of forage available on the fields. Thus, rainfall, rangeland regimes and grazing intensity were used to define sampling classes based on the assumption that these are major factors affecting the quality and condition of the rangelands.

\subsection{Aboveground biomass (AGB) harvesting}

A total of thirty six field plots (each plot measuring $100 \mathrm{~m} \times 100 \mathrm{~m}$ ) were sampled from the entire study area (Figure 2). Five $2 \mathrm{~m} \times 2 \mathrm{~m}$ sub-plots were sampled within each plot, one at the centre of the plot and four at the four corners of each sub-plot using a quadrat (Ray \& Murray, 1996) for harvesting AGB and estimating other biophysical parameters (Pasolli et al., 2008). Within each plot and sub-plot, Easting and Northing coordinates using a Garmin GPS at $\pm 3 \mathrm{~m}$ accuracy level, proportion of bare ground (\%), and indicators of erosion (m) were recorded. Thereafter, all the grass in the sub-plots in which the boundary was set using a quadrat covering $4 \mathrm{~m}^{2}$ were cut at 
the ground level and immediately weighed to obtain a wet weight $(\mathrm{kg})$ of the grass. The collected material was transferred to the laboratory where the samples were dried in the oven at $75^{\circ} \mathrm{C}$ for $72 \mathrm{hrs}$ and weighed again to measure the water content and total dry biomass.

Foliage of trees and shrubs estimation was made using the Kirms \& Norton (1985) and Bonhan (1989) reference unit method from the sample entire quadrat measuring $100 \mathrm{~m} \times 100 \mathrm{~m}$. Plant parts such as shoots, which are small units of given proportions, were designated as reference units (Bonhan 1989). According to Kirms \& Norton (1985) and Kamau (2004), the estimated weight of the reference unit was $10-20 \%$ of the foliage weight of the typical plant in size. Nevertheless, in this study reference units equated to $10-30 \%$ as the low rainfall areas were primarily consist of woody materials with fewer leaves. Average green part of plants was clipped from reference units and green weight was established. The typical weight of clipped reference unit was multiplied by the total number of estimated reference units to determine biomass production (Bonham 1989). Then the whole reference unit was dried in the oven at $75^{\circ} \mathrm{C}$ for 72 hours and weighed to determine the dry weight. Platis \& Papanastasis (2003) measured the spatial distribution of available biomass in kermes oak shrublands by means of high resolution aerial photographs to determine the quantity of available biomass. The regression of available forage with shrub cover measured on the ground and on aerial photographs produced higher coefficient of determination $\left(R^{2}>0.70\right)$ when the shrub height was up to $0.5 \mathrm{~m}$. This suggests that measuring shrub cover on aerial data can be utilized to estimate available biomass in shrublands.

\subsection{Satellite Imagery}

Satellite Pour l'Observation de la Terre 5 (SPOT-5) multispectral imagery (10 m x $10 \mathrm{~m}$ ) was acquired from the South African National Space Agency (SANSA) for the study sites for dates between February 28, 2014 and April 6, 2014 to correspond with the dates when the field data was collected. The satellite imagery data was atmospherically corrected and converted to reflectance using the Cos (t) model (Chavez 1996) to reduce variability of vegetation indices due to the heterogeneity in the radiometric processing of data (Guyot \& Gu 1994). All images were georectified using nearest-neighbour resampling technique.

The satellite imagery data was atmospherically corrected and converted to reflectance using the Cos (t) model (Chavez 1996) to reduce variability of vegetation indices due to the heterogeneity in the radiometric processing of data (Guyot \& Gu 1994). All images were georectified using nearestneighbour resampling technique in ArcGIS 10.3 environment. Then the indices were calculated (NDVI using equation 1, SAVI using equation 2 and SMA using equation 3) using Erdas IMAGINE.

$$
\begin{aligned}
& N D V I=N I R-\text { Red } / \text { NIR }+ \text { Red } \\
& S A V I=((N I R-\text { Red }) /(N I R+\operatorname{Red}+L)) *(1+L) \\
& S R(\lambda)=\sum_{k}^{n} E M_{\mathrm{ir}} f_{\mathrm{ir}}+\varepsilon_{\mathrm{i}}
\end{aligned}
$$$$
\text { Equation } 1
$$$$
\text { Equation } 2
$$$$
\text { Equation } 3
$$ 
where:

$N I R=$ Near infrared, band 3

$L=$ is a canopy background adjustment factor

$S R(\lambda)=$ is the apparent surface reflectance of a pixel in an image or band.

$E M_{\text {ix }}=$ relative radiance in band i for each endmembers.

$f_{\text {ir }}=$ fraction of each image endmember k calculated band by band.

$\varepsilon_{\mathrm{i}}=$ reminder between measured and modelled DN (band residuals).

\subsection{Data analysis}

Numerous studies have indicated that NDVI can be used for the estimation of AGB and other vegetation characteristics when there is a gradual increase of green vegetation up to a certain quantity. For example, Khajedeen (1995) indicated that NDVI was the most suitable index for analysis, management and studying rangeland productivity in semi-arid regions. Paruelo et al. (2000) found that NDVI had a higher correlation with the Annual Net Primary Production (ANPP) $\left(\mathrm{R}^{2}=0.74 \%\right)$ even though the plant cover rates were low. Sepehri (2003) demonstrated that in regions with high percentage of plant cover; NDVI was highly correlated with plant cover. Similarly, Farzadmehr et al. (2004) in their study performed in the Semirom semi-arid region, Iran estimated that the correlation between NDVI and plant cover data was significant at $\mathrm{p} \leq 0.05$.

By making use of the ArcGIS spatial analyst tools, the above-ground biomass map was prepared using the regression models. These relationships were applied to the pixels identified as grasslands based on a land cover map which was derived from the satellite data. A land use and land cover map which was produced using a maximum likelihood classification method was used to mask shrub lands to separate grasslands from shrub lands using the Kirms \& Norton (1985) and Bonham (1989) reference unit technique, available forage was predicted.

NDVI, SAVI and SMA were subsequently computed. Using different regression models, then a relationship was established between AGB data as a dependent variable and the derived remote sensing variables (NDVI, SAVI and SMA) as independent variables. The purpose of this process was to generate the appropriate independent variable (vegetation indices and fractions), which could provide the best estimated results (vegetation indices: $\leq 0$ showing absence of vegetation and 1 is ideal, while the SMA $=0 \%$ is bareground and $100 \%$ is ideal at $\mathrm{P} \leq 0.05$ ). Estimation of forage quantity from the vegetation indices (NDVI and SAVI) and SMA was performed by relating them with AGB, which was then used to develop a regression model. Figure 3 shows the major steps for producing these models. The best fitted (based on the significance level) models were used to create biomass distribution maps of the study sites. 


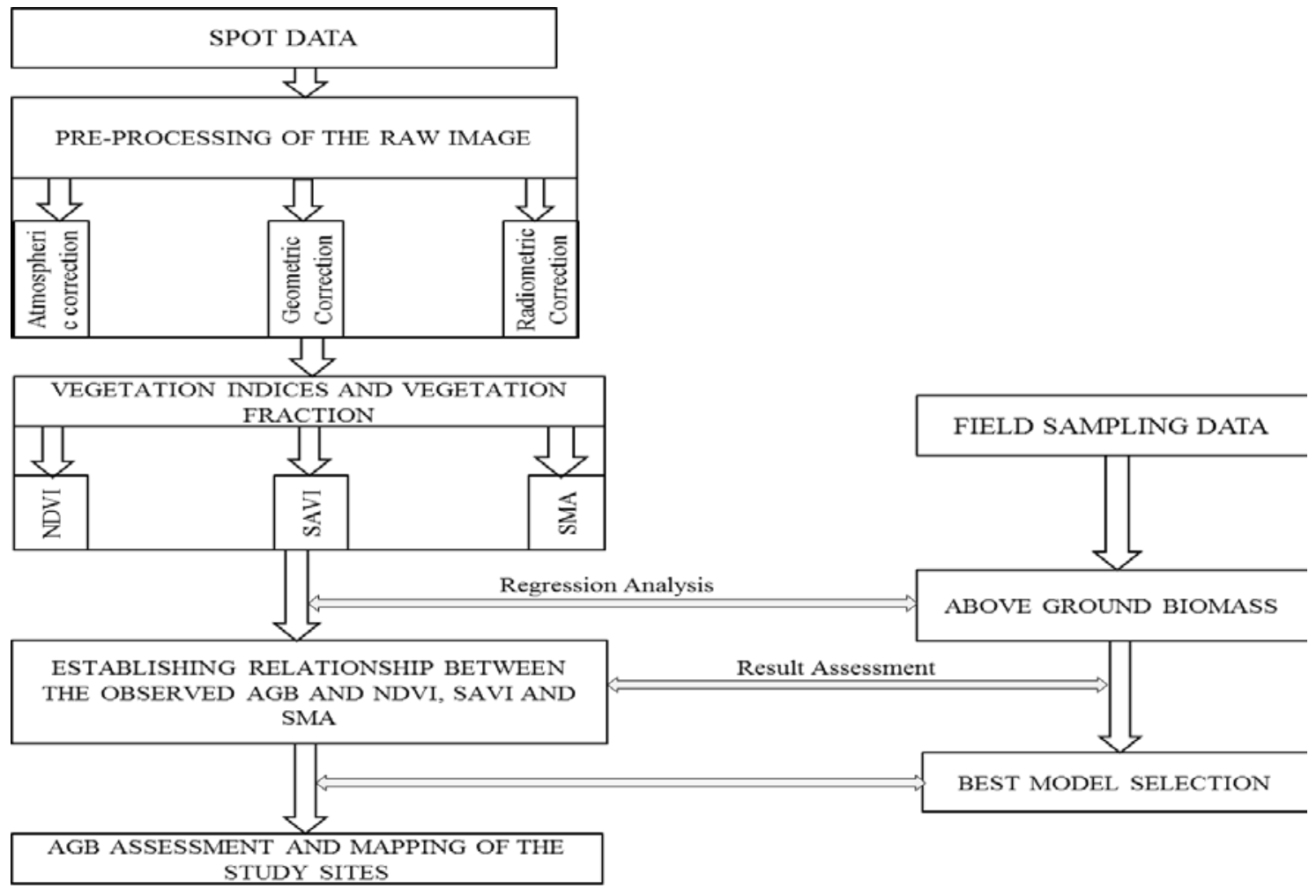

FIG. 3. Flow chart showing major steps of the study

\section{Results}

Three statistical regression models were executed in order to compare the performance of the vegetation indices and the vegetation fraction for estimating the AGB. A result with the best coefficient of determination was used for mapping the distribution of the AGB in the study sites (Figure 4). 


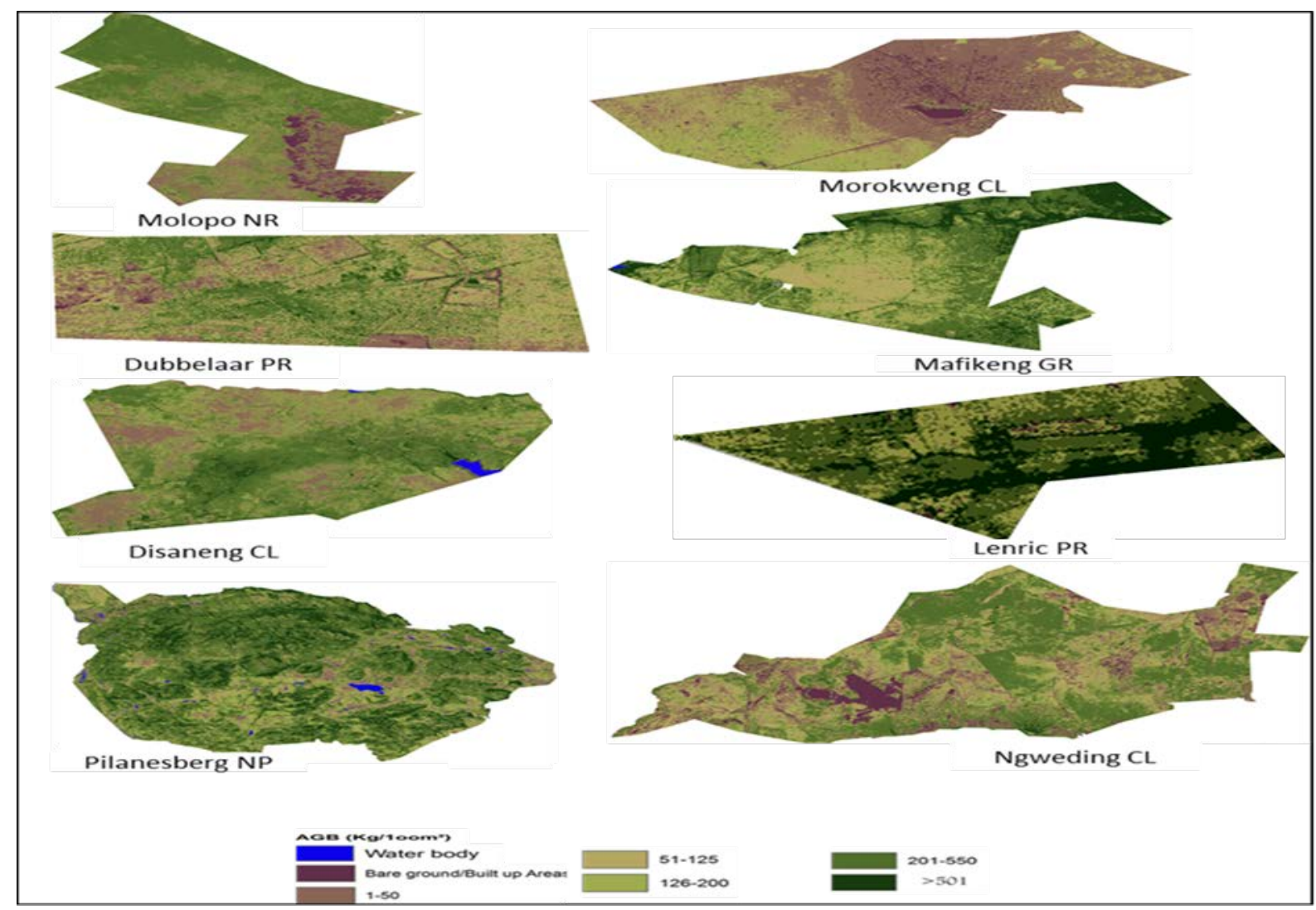

FIG. 4. Aboveground biomass distribution maps of the study sites.

Note: CL (communal land), PR (private ranch), NR (nature reserve), NP (national park), GR (game reserve).

Regression models of the AGB as a function of spectral indices (NDVI and SAVI) and vegetation fraction (SMA) were compared. From the high grazing intensity sites in the LRFZ, AGB was not significantly correlated to NDVI and SAVI at $\mathrm{p} \leq 0.05$ (Table 2). However, in the low grazing intensity site and the combined treatments (high grazing intensity and low grazing intensity) the regression coefficient for AGB and NDVI was significant in both linear and non-linear models. Similarly, in this region significant linear and nonlinear coefficient of determination was detected between AGB and SMA in the high grazing intensity and combined. Although the SAVI was a better fit model, both linearly and non-linearly, for estimating biomass for all treatments (high grazing intensity, low grazing intensity and combined) in the low rainfall zone than NDVI and SMA, no regression coefficient was significant at $\mathrm{p} \leq 0.05$. 
Table 2. Coefficients of determination $\left(\mathrm{R}^{2}\right)$ between NDVI, SAVI, and SMA and aboveground biomass

\begin{tabular}{|c|c|c|c|c|c|c|c|c|c|c|}
\hline \multirow[b]{2}{*}{ 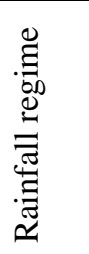 } & \multirow[b]{2}{*}{ 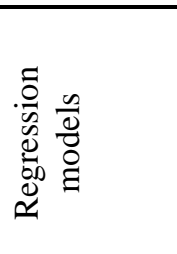 } & \multicolumn{3}{|c|}{ NDVI-AGB $\left(\mathrm{R}^{2}\right)$} & \multicolumn{3}{|c|}{ SAVI-AGB $\left(\mathrm{R}^{2}\right)$} & \multicolumn{3}{|c|}{ SMA-AGB $\left(\mathrm{R}^{2}\right)$} \\
\hline & & HGI & LGI & 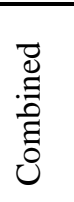 & HGI & LGI & 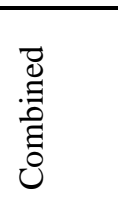 & HGI & LGI & 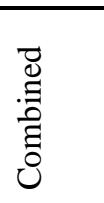 \\
\hline \multirow{3}{*}{ 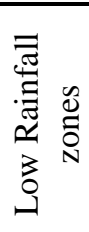 } & Linear & 0.25 & 0.44 & $\begin{array}{l}0.46 \\
* *\end{array}$ & 0.52 & 0.56 & 0.64 & $0.34^{*}$ & 0.105 & $0.44^{*}$ \\
\hline & Exponential & 0.28 & $0.49 *$ & $\begin{array}{l}0.47 \\
* *\end{array}$ & 0.53 & 0.58 & 0.55 & $0.35^{*}$ & 0.110 & $0.53^{*}$ \\
\hline & Quadratic & 0.18 & 0.27 & $\begin{array}{l}0.46 \\
* *\end{array}$ & 0.63 & 0.57 & 0.64 & $0.35^{*}$ & 0.095 & $0.45^{*}$ \\
\hline \multirow{3}{*}{ 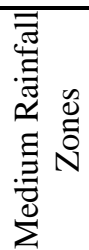 } & Linear & $0.37 *$ & $0.44^{*}$ & $\begin{array}{l}0.63 \\
*\end{array}$ & $0.37 *$ & $\begin{array}{l}0.36 \\
*\end{array}$ & $0.60^{* *}$ & 0.14 & 0.27 & $0.51^{* *}$ \\
\hline & Exponential & $0.38^{*}$ & $0.40^{*}$ & $\begin{array}{l}0.54 \\
*\end{array}$ & $0.38 *$ & $\begin{array}{l}0.37 \\
*\end{array}$ & $0.57^{*}$ & 0.22 & 0.28 & $0.48^{* *}$ \\
\hline & Quadratic & $0.38^{*}$ & $0.45 *$ & $\begin{array}{l}0.53 \\
*\end{array}$ & $0.38 *$ & $\begin{array}{l}0.45 \\
*\end{array}$ & $0.53^{* *}$ & 0.20 & 0.27 & $0.50^{* *}$ \\
\hline \multirow{3}{*}{ 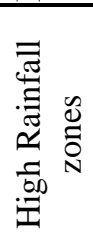 } & Linear & $0.39 * *$ & $\begin{array}{l}0.72 * \\
*\end{array}$ & $\begin{array}{l}0.70 \\
* *\end{array}$ & $0.48^{*}$ & 0.49 & $0.69 * *$ & 0.16 & 0.13 & $0.51^{*}$ \\
\hline & Exponential & $0.39 * *$ & $\begin{array}{l}0.65 * \\
*\end{array}$ & $\begin{array}{l}0.55 \\
* *\end{array}$ & $0.45^{*}$ & 0.43 & $0.64 * *$ & 0.19 & 0.12 & $0.57^{*}$ \\
\hline & Quadratic & $0.41^{* *}$ & $\begin{array}{l}0.61^{*} \\
*\end{array}$ & $\begin{array}{l}0.63 \\
* *\end{array}$ & $0.48^{*}$ & 0.50 & $0.59 * *$ & 0.16 & 0.14 & $0.61^{*}$ \\
\hline
\end{tabular}

Note: * Correlation is significant at $\mathrm{P} \leq 0.05$ level, ** Correlation is significant at $\mathrm{P} \leq 0.01$ level. (NDVI, normalized vegetation index; SAVI, soil adjusted vegetation index; SMA, spectral mixture analysis; AGB, above ground biomass; HGI, high grazing intensity; LGI, low grazing intensity

All linear and non-linear coefficients of determination between AGB and NDVI were significant for all treatments (high grazing intensity, low grazing intensity and combined) in the medium rainfall zones at $\mathrm{p} \leq 0.05$. SMA was poorly correlated to AGB in the high grazing intensity sites and low grazing intensity sites in the medium rainfall zones. However, the combined treatment's coefficient of determination between AGB and SMA was significant with coefficients of determination of $0.44,0.53$ and 0.45 for linear, exponential and quadratic models respectively. Significant and stronger coefficients of determination were detected between AGB and NDVI in all sites in the high rainfall zones for both linear and non-linear models.

Similarly, significant coefficient of determination was detected between SAVI and AGB in the high rainfall zone, although the regression coefficients between AGB and SAVI was not significant at $\mathrm{p} \leq 0.05$ in the low grazing intensity sites. The coefficient of determination between SMA and AGB was not significant in the high grazing intensity and low grazing intensity sites in the high rainfall zone but the coefficient of determination for the combined treatment in linear and non-linear relation was highly significant. This is similar to results of previous studies that found a highly significant correlation coefficients (Gamon et al. 1995; Barati et al. 2011). 


\section{Discussion}

For high grazing intensity and low grazing intensity sites in the low rainfall zone, the coefficients of determination between above ground biomass (AGB) and NDVI were lower than those for SAVI and SMA. The coefficient of determination between AGB and NDVI in the combined grazing intensity treatments was significant at $\mathrm{P} \leq 0.05$. The low coefficient of determination between AGB and NDVI in the low rainfall areas might be attributed to the effect of soil background as the region is characterized by sparse vegetation with a higher proportion of bare ground and abundance of non-photosynthetic materials such as dry stems and dry leaves (Moussa et al., 2009). Where values of vegetation cover are low, the different nature of soil backgrounds contributes additives differently leading to interferences with spectral signatures in areas where ground cover values are high by back-scatter (Huete et al. 1988; Fredrickson 1993). Hence, spectral indices have a limitation of not being able to minimize soil background effects particularly in the low rainfall areas. This effect can be a major limiting factor in quantitative assessment of AGB.

Both vegetation indices (NDVI and SAVI) were poorer predictors of biomass in high grazing intensity sites than in low grazing intensity sites, probably due to the presence of senescent or dry vegetation and higher proportion of bare soil. Higher grazing intensity sites have greater proportions of standing dead and litter components and higher proportion of bare grounds relative to grazed sites. Since non-photosynthetic vegetation displays higher visible reflectance, indices which rely on the contrast between visible and near-infrared reflectance lose their ability to determine the quantity of vegetation biomass. The higher visible and infrared reflectance pattern of dry vegetation also restricts the response of spectral index to biomass quantity. The contrast between green biomass and dry soil is reduced as vegetation dries (Tueller, 1996; Moussa et al., 2009). Therefore, the spectral indices respond less to biomass variation.

Thus, the NDVI proved to be the most efficient estimator of AGB in the combined (high grazing intensity and low grazing intensity sites) in medium and high rainfall zones. Comparable to the vegetation indices tested in this study, NDVI confirmed to be the most accurate indicator of grass biomass. Similarly, Lawrence \& Ripple (1998) indicated that none of the indices that they used such as Simple Ratio (SR), SAVI, Optimized SAVI, TSAVI, Modified SAVI and GVI is more accurate than NDVI for estimation of vegetation cover fraction in arid and semi-arid areas. In their study, the correlation of determination obtained from Transformed Soil Adjusted Vegetation Index (TSAVI) was 0.62, SR was 0.60, OSAVI was 0.59, MSAVI was 0.55, SAVI was 0.55, GVI 0.40 while for NDVI was 0.65. Similarly, the SAVI computed by Baugh \& Groeneveld (2006) had lower coefficient of determinations of 0.43 with antecedent rainfall.

\section{Conclusion}

In this study, SPOT 5 multispectral imagery was found to be very useful for assessing live biomass in the North West province of South Africa. The relationships of the NDVI and the biomasses of the study sites showed a wider range of possible values, growing in various types of 
rainfall zones, soils of varying characteristics, and on slopes of variable steepness. Regarded as critical for sustained supply of essential ecosystem goods and services, satellite data accurately measured indicators of rangeland biomass and allowed the production of biomass maps that are open to repeatable and inexpensive updating. Such maps can be used to assess risks of soil erosion as well as vegetation cover change. In addition, in spite of its weakness in the low rainfall areas, NDVI displayed stronger coefficients of determination with AGB. Hence, NDVI was found to be the most efficient vegetation index for quantifying AGB in the North West province and possibly in similar arid and semi-arid environments.

\section{Acknowledgements}

Funding for this study was afforded by the North-West University. We are grateful to the university for providing logistical and financial assistance, as well as the North West Province Parks and Tourism board for their assistance during fieldwork.

\section{REFERENCES}

Angerer, J., G. Sean and T. Doug. 2009, Technology Transfer Part I: Implementation of the Livestock Early Warning System in Mongolia. Global Livestock CRSP, Research Brief 09-01- GOBI, Univ. of CaliforniaDavis.

Barati, S., Rayegani, B., Saati, M., Sharifi, A. and Nasri, M. 2011, Comparison the accuracies of different spectral indices for estimation of vegetation cover fraction in sparse vegetated areas. The Egyptian Journal of Remote Sensing and Space Sciences 14, 49 -56.

Baugh, W.M., \& Groeneveld, D.P., 2006, Broadband vegetation index performance evaluated for a lowcover environment. International Journal of Remote Sensing 27, 4715-4730.

Bonham CD (1989) Measurements for terrestrial vegetation. New York: Wiley, 354 p

Booth, D.T., \& Tueller, P.T. 2003, Rangeland Monitoring Using Remote Sensing. Journal of Arid Land Research and Management, 17, 455-467.

Brown M.E., Pinzon J.E., Didan K., Morisette J.T. and Tucker C. J. 2006, Evaluation of the consistency of long-term NDVI time series derived from AVHRR, SPOT-vegetation, SeaWiFS, MODIS, and Landsat ETM+ sensors. IEEE Transactions on Geoscience and Remote Sensing, 44, 1787-1793.

Chavez, P.S. 1996, Image-Based Atmospheric Corrections - Revisited and Improved, Photogrammetric Engineering \& Remote Sensing, 62 (9): 1025-1036.

Clevers, J.G.P.W. \& Kooistra, L. 2012, Using Hyperspectral RemoteSensing Data for Retrieving Canopy Chlorophyll and Nitrogen Content. IEEE Journal of Selected Topics in Applied Earth Observation and Remote Sensing, 5(2), pp. 574-583.

Daubenmire, R. 1959, A canopy-cover method of vegetation analysis. Northwest Science, 33:43-46.

Dube, O., \& Pickup, G. 2001, Effects of rainfall variability and communal and semi-commercial grazing on land cover in southern African rangelands. Journal of Climate Research, 17, 195-208. 
Elmore, A. J., Mustard, J. F., Manning, S. J., and Lobell D. B. 2000, “Quantifying Vegetation Change in Semiarid Environments: Precision and Accuracy of Spectral Mixture Analysis and the Normalized Difference Vegetation Index,” Remote Sensing of Environment, 73:87-102.

FAO (2009): Climate and Rainfall. http://wwww.fao.org/wairdocs/ilri/x5524e/x5524e03.htm (Accessed on 26 February 2014).

Farzad mehr, H. Arzani, H. Darvish, A. and Jafari. M. 2004, The study of Landsat TM image data for estimate production and vegetation cover in Hanna-Semirom. Iranian Journal of Natural Resources 57, 2, 339-350.

Fredrickson E.L., Estell R.E., and Remmenga M.D. 2007, Volatile compounds on the leaf surface of intact and regrowth tarbush (Flourensia cernua DC) canopies. Journal of Chemical Ecology, 33:1867-1875.

Gamon, J.A., Field, C.B., Goulden, M., Griffin, K., Hartley, A., Joel, G., Penuelas J., and Valentini, R. 1995, Relationships between NDVI, canopy structure, and photosynthetic activity in three Californian vegetation types. Ecological Application 5: 28-41.

Gitelson, A. A. 2004, Wide dynamic range vegetation index for remote quantification of biophysical characteristics of vegetation. Journal of Plant Physiology, 161, 165-173.

Guo, LD., Semiletov, I., Gustafsson, O., Ingri J., Andersson, P., Dudarev, O., and White D. 2004, Characterization of Siberian Arctic coastal sediments: Implications for terrestrial organic carbon export, Global Biogeochemical Cycles, 18, GB1036, doi:10.1029/2003GB002087.

Guyot, G, \& Gu, XF 1994, Effect of radiometric corrections on NDVI determined from SPOT HRV and Landsat TM data. Remote Sensing of Environment, 49, 169 - 180

Hoffman, MT., Cousins, B, Meye, RT, Petersen, A and Hendricks, H 1999, Historical and contemporary land use and the desertification of the Karoo. In: The Karoo: Ecological Patterns and Processes. Eds Dean, and Milton, S.J., Cambridge University Press, Cambridge, 257-273.

Hoffman, MT, \& Todd, S 2000, National review of land degradation in South Africa: The influence of biophysical and socio- economic factors. Journal of South African Studies, 26,743-758.

Hudson, JW 2002, Responses to climate variability of the livestock sector in the North-West Province, South Africa. M.A. Thesis, Colorado State University, Fort Collins, CO.

Huete, A, Didan, K, Miura, T, Rodriguez, EP, Gao, X, and Ferreira, LG 2002, Overview of the radiometric and biophysical performance of the MODIS vegetation indices. Remote Sensing of Environment 83, 195213.

Huete, AR 1988, A soil-adjusted vegetation index (SAVI). Remote Sensing of Environment, 25: 295-309.

Jarocinska, A, \& Zagajewski, B 2006, Remote sensing tools for analysis of vegetation condition in extensively used agricultural areas. University of Warsaw, K Krakowskie Przedmiescie 30, 00-927 Warszawa, Poland.

Kamau, P. (2004): Forage Diversity and Impact of Grazing Management on Rangeland Ecosystems in Mbeere District, Kenya. LUCID Working Paper Series Number: 36.

Kirmse, R.D. and B.E. Norton. 1985. Comparison of the reference unit method and dimension analysis methods for two large shrubby species in the Caatinga woodlands. J. Range Manage. 38:425-428. 
Lawrence, RL \& Ripple, WJ 1998, “Comparisons Among Vegetation Indices and Bandwise Regression in a Highly Disturbed, Heterogeneous Landscape: Mount St. Helens, Washington,” Remote Sensing of Environment, 64:91-102.

Li, JL, Zhang, J, Zhang, C and Chen, QG 2006, “Analyze and Compare the Spatial Interpolation Methods for Climate Factor,” Pratacult Science, 23, (8), 2006, 6-11.

Liu, Y, Zha Y, Gao J, and Ni S 2004, Assessment of grassland degradation near Lake Qinhai, West China, using Landsat TM and in situ reflectance spectra data. International Journal of Remote Sensing, 25: 41774189.

Mangold, S, Momberg, M and Newbery, R 2002, Biodiversity and Conservation. In: Mangold, S., KaluleSabiti, M. \& Walmsley, J. (eds.). State of the Environment Report, North West Province, South Africa, Chapter 11. NWDACE.

Masigo, A, \& Matshego, C, 2002, Provincial report on education and training for agriculture and rural development in North West Province. North West: North West Department of Agriculture, Conversation and Environmental.

Mountrakis, G, Im, J, and Ogole, C 2011, Support vector machines in remote sensing: A review. ISPRS Journal of Photogrammetry and Remote Sensing, 66(2011), 247-259.

Moussa, AS., van Rensburg, L, Kellner, K and Bationo, A 2009, Exploring differences of soil quality as related to management in semiarid rangelands in the western Bophirima District, North West Province, South Africa. African Journal of Range \& Forage Science, 26, 27-36.

Munyati, C \& Mboweni, G 2013, Variation in NDVI values with change in spatial resolution for semi-arid savanna vegetation: a case study in northwestern South Africa. International Journal of Remote Sensing, 34 (7), 2253-2267.

Mutanga, O, Mansour, K, Everson, T, Skidmore, A and Kumara, L 2012, "High density biomass estimation for wetland vegetation using WorldView- 2 imagery and random forest regression algorithm." International Journal of Applied Earth Observation and Geoinformation, 18(0): 399-406.

Numata, I, Dar, AR, Oliver, A, Chadwick, JS, Fernando, RS, Francisco, CL., and João, VS 2007, Characterization of pasture biophysical properties and the impact of grazing intensity using remotely sensed data. Remote Sensing of Environment, 109, 314-327.

Paruelo, JM, Oesterheld, M, Di Bella, CM, Arzadum, M, Lafontaine, J, and Cahuepe', M 2000, Estimation of primary production of subhumid rangelands from remote sensing data. Applied Vegetation Science, 3, 189-195.

Pasolli L, Melgani F, Blanzier E 2008, Estimating Biophysical Parameters from remotely sensed imagery with Gaussian processes, University of Trento Press, 14, I-38100, Italy.

Platis, P.D., Papanastasis, V.P. (2003): Relationship between shrub cover and available forage in Mediterranean shrublands. Agroforestry Systems, 57, 59-67.

Ray, TW \& Murray, BC 1996, Nonlinear spectral mixing in desert vegetation. Remote Sensing of Environment, 55: 59-64. 
Schultze, RE 1997, South African Atlas of Agrohydrology and Climatology. Water Research Commission, Pretoria, Report TT 82/96.

Shackleton, CM 1993, Are the communal grazing lands in need of saving? Development Southern Africa, 10 (1): 65-78.

Silleos, NG, Alexandridis, TK, Gitas, IZ and Perakis, K 2006, Vegetation Indices: Advances made in Biomass Estimation and Vegetation Monitoring in the last 30 Years, Geocarto International, 21 (4) 21-28.

Snyman, HA 1998, Dynamics and sustainable utilization of the rangeland ecosystem in arid and semi-arid climates of southern Africa. Journal of Arid Environment, 39, 645-666.

Tucker, JC, Pinzon, EJ, Brown, EM, Slayback, AD, Pak, WE and Mahoney, R 2005, An extended AVHRR 8-km NDVI dataset compatible with MODIS and SPOT vegetation NDVI data. International Journal of Remote Sensing, 26, 4485-4498.

Tueller, PT 1989, Remote sensing technology for rangeland management applications, Journal of Range Management, 42, 442-453.

Tueller, PT 1996, Near Earth Monitoring of Range Condition and Trend. Journal of Geocarta, 11, 53-62.

Ullah, S, Schlerfa, M, Skidmorea, AK and Heckera, C 2012, Identifying plant species using midwave infrared $(2.5-6 \mu \mathrm{m})$ and thermal infrared $(8-14 \mu \mathrm{m})$ emissivity spectra. Remote Sensing of Environment, 118, 95102.

Vogel, C and O’Brien, K 2003, Climate Forecasts in Southern Africa, in O’Brien, K., Vogel C. (eds) (2003): Coping with Climate Variability: the Use of Seasonal Climate Forecasts in Southern Africa, Ashgate Press, Aldershot, 3-34.

Wessels, KJ, Prince, SD, Frost, PE and van Zyl, D 2004, Assessing the effects of human-induced land degradation in the former homelands of northern South Africa with a $1 \mathrm{~km}$ AVHRR NDVI time-series. Remote Sensing of Environment, 91, 47-67.

Wessels, K.J., Prince, S.D., Carroll, M., Malherbe, J. (2007): Relevance of rangeland degradation in semiarid northeastern South Africa to the nonequilibrium theory. Ecological Applications, 17, 815-827.

Wu, W, De Pauw E and Hellden U 2013, Assessing woody biomass in African tropical savannahs by multiscale remote sensing. International Journal of Remote Sensing 34: 4525-4529.

Yang, YH, Fang, JY, Pan, YD and Ji CJ 2009, Aboveground Biomass in Tibetan Grasslands. Journal of Arid Environments 73: 91-95.

Zoran, M and Stefan, S 2006, Climatic changes effects on spectral vegetation indices for forested areas analysis from satellite data. Proceedings of the 2nd Environmental Physics Conference, 18-22 February 2006, Alexandria, Egypt, pp.73. 